\title{
Serum Beclin 1 and autophagy-related protein-5 and the risk of hepatocellular carcinoma among cirrhotic hepatitis $C$ patients
}

\author{
Ayman El Shayeb ${ }^{1}$, Akram Deghedy ${ }^{2}$, Essam Saeed Bedewy ${ }^{1}$, Sahar Badawy ${ }^{1 *}$ and Nermeen Abdeen ${ }^{1}$
}

\begin{abstract}
Background: The most common primary liver cancer in adults is hepatocellular carcinoma (HCC) which is commonly presented with a poor prognosis. Therefore, it is important to explore effective biomarkers and therapeutic targets for HCC patients. Autophagy is involved in the development and prevention of cancer. Mammalian Beclin-1 is needed for an autophagic vesicle in HCC. Autophagy-related protein-5 (ATG5) is an important molecule involved in cell death during autophagy. The objective is to investigate serum ATG 5 and Beclin 1 levels in HCV-induced liver cirrhosis with and without HCC. The study was conducted on 80 individuals classified into 3 groups:
\end{abstract}

Group 1: 30 patients with HCV-induced liver cirrhosis without HCC.

Group 2: 30 patients with HCV-induced liver cirrhosis with HCC.

Group 3: 20 healthy subjects (control group).

Results: Serum ATG 5 was significantly lower in HCC than liver cirrhosis patients. Serum Beclin 1 was significantly higher in HCC than liver cirrhosis patients. A cutoff value of $<95.7$ and $>5.3$ of serum ATG5 and Beclin 1 could be suggested for diagnosis of HCC among patients with HCV-related cirrhosis.

Conclusion: Serum Beclin 1 and ATG 5 could be used as a novel diagnostic marker for HCC. Moreover, scoring of serum BECLIN 1, ATG 5, and cachexia might be a future promising tool to predict the risk of HCC development.

Keywords: Liver cirrhosis, Hepatocellular carcinoma, Hepatitis C virus, Serum Beclin 1, Serum ATG5

\section{Background}

Hepatocellular carcinoma (HCC) is the fifth most common cancer and the second most common cause of cancer-related death worldwide accounting for $7 \%$ of all cancers [1]. The most frequent risk factor for HCC is cirrhosis. All causes of cirrhosis can be complicated by $\mathrm{HCC}$, but the risk increased in patients with viral hepatitis. Moreover, around one-third of cirrhotic patients will develop HCC during lifetime [2]. The autophagic

\footnotetext{
*Correspondence: saharbadawy70@gmail.com

${ }^{1}$ Tropical Medicine Department, Faculty of Medicine, Alexandria University, Alexandria, Egypt

Full list of author information is available at the end of the article
}

response is deregulated in chronic liver conditions which can develop HCC [3].

Autophagy has a pro-survival function during HCC. Increased autophagy flux was detected in advanced cases of HCC and an increased autophagy response was found to be associated with malignant development and poor prognosis of HCC $[4,5]$. Autophagy helps HCC invasion by having effect on the epithelial-mesenchymal transition [6]. It explains why HCC develops in cirrhotic liver rather than in normal liver.

BECLIN1 is a dual function molecule which acts as a tumor suppressor and autophagy regulator [7]. Mice with alteration of BECLIN1 showed a decreased 
autophagy activity and the formation of malignant lesions like HCC [8].

Autophagy-related protein-5 (ATG5) can control autophagy. Calpain 1 is a calcium-dependent non-lysosomal cysteine protease that digests ATG5 [9]. Low intracellular calcium levels decrease the cleavage activity of Calpain 1, increase the level of ATG5 and ATG12-ATG5 and increase autophagy [10]. MicroRNA (miR181a) interacts with a miRNA response element in the $3^{\prime}$ untranslated region (UTR) of $A T G 5$, which inhibits its transcription. Increased expression of miR181a decreases ATG5 mRNA and protein levels, resulting in autophagy inhibition [11].

The aim of the work is to evaluate the level of serum Beclin1 and serum ATG5 among cirrhotic hepatitis $C$ virus patients with and without hepatocellular carcinoma.

\section{Subjects}

This study was conducted on 80 individuals admitted to the Tropical Medicine Department of Alexandria Main University Hospital during the period from October 2018 to January 2020 who were divided into 3 groups:

Group 1: 30 patients with HCV-induced liver cirrhosis without $\mathrm{HCC}$

Group 2: 30 patients with HCV-induced liver cirrhosis with HCC

Group 3: 20 healthy subjects of matched age and sex as control

Informed consent was taken from every participant in this study.

\section{Exclusion criteria}

Patients with chronic HBV infection, any other identifiable cause of chronic hepatitis other than $\mathrm{HCV}$, and patients with any suspected malignancies other than HCC, diabetes mellitus, chronic kidney disease, coronary disease, organ transplantation, and autoimmune hepatitis were excluded.

\section{Methods}

All participants were subjected to a detailed history taking and clinical assessment. The presence or absence of cirrhosis and HCC existence were documented by an ultrasound followed by a triphasic CT for those who had suspected focal hepatic lesions.

Serum AFP [12], Beclin 1 [13], and ATG 5 [14] levels were measured by using an enzyme linked immunosorbent assay (ELISA) according to the manufacturer's instructions.

\section{Statistical analysis of the data [15]}

Data were fed to the computer and analyzed using IBM SPSS software package version 20.0 [16]. Qualitative data were described using number and percent. Quantitative data were described using range (minimum and maximum), mean, standard deviation, and median. Comparison between the three studied groups regarding categorical variables was tested using Chi-square test.

For normally distributed data, comparison between the three studied groups was analyzed, $F$-test (ANOVA) to be used and post hoc test (Scheffe). For abnormally distributed data, comparison between two independent population were done using Mann-Whitney test while Kruskal-Wallis test was used to compare between the three studied groups and pair wise comparison was assessed using Mann-Whitney test. Correlations between two quantitative variables were assessed using Spearman coefficient.

Receiver operating characteristic curve (ROC) was plotted to analyze a recommended cutoff for the 3 markers; the area under the ROC curve denotes the diagnostic performance of the test. Multivariate logistic regression was performed.

\section{Results}

Table 1 lists the demographic data between liver cirrhosis, HCC patients, and control group as regards age, sex, MELD score, Child-Pugh score, and BCLC.

In cirrhotic patients, the number of patients with cachexia was 7 out of 30 with $23.3 \%$. In HCC patients, the number of patients with cachexia was 17 out of 30 with $56.7 \%$. There was higher statistical significance of cachexia in patients with HCC than patients with liver cirrhosis ( $p$ value $<0.001)$ as shown in Table 2.

In HCC patients, 15 patients preseAls with portal vein thrombosis (PV). As regards multicentricity, there were 20 patients that presented with multiple lesions of HCC lesions, while 10 patients presented with single lesion as shown Table 3.

Serum alpha-fetoprotein was significantly higher in HCC patients than cirrhotic patients and control group $\left(p 0.025, p<0.001^{*}\right)$. Also, there was statistically significant difference between cirrhosis and control group ( $p$ value 0.001 ) as shown in Table 4.

Serum ATG 5 was significantly lower in patients with HCC than in patients with cirrhosis and control group ( $p$ value $0.022, p$ value 0.001 ). But there was no statistically significant difference between patients with cirrhosis than control individuals ( $p$ value 0.258 ) as shown in Table 5.

Serum Beclin 1 was significantly higher in HCC patients than cirrhotic patients and control group $(p$ 
Table 1 Comparison between the three studied groups according to different parameters

\begin{tabular}{|c|c|c|c|c|c|}
\hline & $\begin{array}{l}\text { Cirrhotic } \\
(n=30)\end{array}$ & $\begin{array}{l}\text { HCC } \\
(n=30)\end{array}$ & $\begin{array}{l}\text { Control } \\
(n=20)\end{array}$ & Test of Sig & $p$ \\
\hline \multicolumn{6}{|l|}{ Sex } \\
\hline Male & $15(50 \%)$ & $19(63.3 \%)$ & $10(50 \%)$ & $x^{2}=$ & 0.510 \\
\hline Female & $15(50 \%)$ & $11(36.7 \%)$ & $10(50 \%)$ & 1.347 & \\
\hline \multicolumn{6}{|l|}{ Age (years) } \\
\hline Mean \pm SD & $58.1 \pm 6.8$ & $55.3 \pm 6$ & $54.3 \pm 4.6$ & $F=2.881$ & 0.062 \\
\hline Median (Min. - Max.) & $56.5(48-75)$ & $54(45-65)$ & $52.5(48-62)$ & & \\
\hline \multicolumn{6}{|l|}{ MELD } \\
\hline Mean \pm SD & $15.1 \pm 4.9$ & $18.9 \pm 5.3$ & - & $t=2.879^{*}$ & $0.006^{*}$ \\
\hline Median (Min. - Max.) & $15(7-24)$ & $19(10-31)$ & - & & \\
\hline \multicolumn{6}{|l|}{ Child Pugh } \\
\hline A & $6(20 \%)$ & $3(10 \%)$ & - & $x^{2}=1.344$ & ${ }^{M C} C_{p}=0.539$ \\
\hline B & $13(43.3 \%)$ & $13(43.3 \%)$ & - & & \\
\hline$C$ & $11(36.7 \%)$ & $14(46.7 \%)$ & - & & \\
\hline Mean \pm SD & $8.9 \pm 2.75$ & $9.5 \pm 2.3$ & - & $U=385.0$ & 0.331 \\
\hline Median (Min. - Max.) & $9(5-14)$ & $9(5-14)$ & - & & \\
\hline \multicolumn{6}{|l|}{$\mathrm{BCLC}$} \\
\hline A & & 3 & & & \\
\hline B & & 9 & & & \\
\hline C & & 4 & & & \\
\hline D & & 14 & & & \\
\hline
\end{tabular}

$\mathrm{X}^{2}$ : Chi square test; MC: Monte Carlo; F: F for ANOVA test

U: Mann Whitney test; $t$ : Student t-test

$\mathrm{H}$ : $\mathrm{H}$ for Kruskal Wallis test, Pairwise comparison bet. each 2 groups were done using Post Hoc Test (Dunn's for multiple comparisons test) $\mathrm{p}$ : $\mathrm{p}$ value for comparing between the studied groups

${ }^{*}$ : Statistically significant at $\mathrm{p} \leq 0.05$

Table 2 Comparison between the three studied groups according to cachexia

\begin{tabular}{|c|c|c|c|c|c|c|c|c|}
\hline \multirow[t]{2}{*}{ Cachexia } & \multicolumn{2}{|c|}{$\begin{array}{l}\text { Cirrhotic } \\
(\mathrm{n}=30)\end{array}$} & \multicolumn{2}{|c|}{$\begin{array}{l}\text { HCC } \\
(n=30)\end{array}$} & \multicolumn{2}{|c|}{$\begin{array}{l}\text { Control } \\
(n=20)\end{array}$} & \multirow[t]{2}{*}{$x^{2}$} & \multirow[t]{2}{*}{$p$} \\
\hline & No & $\%$ & No & $\%$ & No & $\%$ & & \\
\hline No cachexia & 23 & 76.7 & 13 & 43.3 & 20 & 100.0 & $19.365^{*}$ & $<0.001$ \\
\hline Yes & 7 & 23.3 & 17 & 56.7 & 0 & 0.0 & & \\
\hline
\end{tabular}

${ }^{2}$ : Chi square test

$p: p$ value for comparing between the three studied groups

${ }^{*}$ : Statistically significant at $\mathrm{p} \leq 0.05$

Table 3 Distribution of the studied cases according to $C T$ findings in HCC group $(n=30)$

\begin{tabular}{lcc}
\hline CT findings & No & $\%$ \\
\hline PVThrombosis & 15 & 50.0 \\
Number of lesions & & \\
Single & 10 & 33.3 \\
Multiple & 20 & 66.7 \\
\hline
\end{tabular}

value $<0.001, p$ value 0.001$)$. But there was no statistically significant difference between patients with cirrhosis than control individuals ( $p$ value 0.20 ) as shown in Table 6.

The diagnostic performance, cutoff point, sensitivity, specificity, PPV, NPV, and accuracy for discriminating HCC from liver cirrhosis for ATG5, Becline 1, and AFP were shown in Table 7. Receiver operating characteristic 
Table 4 Comparison between the three studied groups according to AFP

\begin{tabular}{llllll}
\hline $\begin{array}{l}\text { AFP } \mathbf{n g} / \\
\mathbf{m l})\end{array}$ & $\begin{array}{l}\text { Cirrhotic } \\
(\mathbf{n}=\mathbf{3 0})\end{array}$ & $\begin{array}{l}\text { HCC } \\
(\mathbf{n}=\mathbf{3 0})\end{array}$ & $\begin{array}{l}\text { Control } \\
(\mathbf{n}=\mathbf{2 0})\end{array}$ & $\mathbf{H}$ & $\mathbf{p}$ \\
\hline Min. - Max & $4.0-200.0$ & $8.0-3200.0$ & $4.0-12.0$ & $39.415^{*}$ & $0.001^{*}$ \\
Mean \pm SD & $39.60 \pm 47.44$ & $442.4 \pm 809.4$ & $7.02 \pm 2.33$ & & \\
Median & 15.0 & 48.50 & 5.0 & & \\
IQR & $10.0-50.0$ & $14.0-800.0$ & $6.0-9.0$ & & \\
Sig. bet. & p1 $=0.025^{*}, \mathrm{p} 2=0.510, \mathrm{p} 3<0.001^{*}$ & & \\
grps & \multicolumn{4}{l}{} \\
\hline
\end{tabular}

$\mathrm{H}: \mathrm{H}$ for Kruskal Wallis test, Pairwise comparison bet. each 2 groups were done using Post Hoc Test (Dunn's for multiple comparisons test)

$p$ : $p$ value for comparing between the studied groups

$p_{1}: p$ value for comparing between Cirrhotic and $\mathrm{HCC}$

$\mathrm{p}_{2}$ : $\mathrm{p}$ value for comparing between Cirrhotic and Control

$p_{3}: p$ value for comparing between $\mathrm{HCC}$ and Control

${ }^{*}$ : Statistically significant at $\mathrm{p} \leq 0.05$ curves (ROC curves) were done to estimate the cutoff points for ATG5, Becline 1, and AFP for predicting the probability for $\mathrm{HCC}$ as shown in Fig. 1.

The diagnostic performance for combined ATG5, Beclin1, and AFP for detection of HCC from cirrhosis was significant, its diagnostic performance was $0.833^{*}$ $(p<0.001 \%)$, with sensitivity of $96.7 \%$, specificity of $63.3 \%$, positive predictive value of $72.5 \%$, negative predictive value of $95 \%$, and accuracy of $80 \%$ as shown in Table 8.

Cachexia, ATG 5 level, Beclin 1, level, AFP, and ChildPugh score were entered in a stepwise logistic regression model; the significant variables were cachexia $\left(P<0.031^{*}\right)$, ATG $5\left(P<0.009^{*}\right)$, and Beclin 1 level $\left(P<0.018^{*}\right)$; on the other hand, the Child-Pugh score was insignificant in the multivariate analysis $(P=0.931)$ and AFP $(P=0.620)$ as shown in Table 9.

Prognostic fidelity was improved when combining these parameters in a scoring system with ATG $5<95.7$, Beclin1 $>5.3$, and presence of cachexia. Cachexia was

Table 5 Comparison between the three studied groups according to ATG5

\begin{tabular}{lllll}
\hline ATG5 $(\mathbf{n g} / \mathbf{m l})$ & $\begin{array}{l}\text { Cirrhotic } \\
(\mathbf{n}=\mathbf{3 0})\end{array}$ & $\begin{array}{l}\text { HCC } \\
(\mathbf{n}=\mathbf{3 0})\end{array}$ & $\begin{array}{l}\text { Control } \\
(\mathbf{n}=\mathbf{2 0})\end{array}$ & H \\
\hline Min. - Max & $44.0-256.5$ & $11.0-149.5$ & $64.40-186.6$ & $11.080^{*}$ \\
Mean \pm SD & $100.8 \pm 50.18$ & $74.08 \pm 32.52$ & $109.2 \pm 34.60$ & $0.004^{*}$ \\
Median & 98.0 & 69.50 & 98.50 & \\
IQR & $62.10-116.6$ & $49.70-95.70$ & $84.95-133.60$ & \\
Sig. bet. grps & $\mathrm{p}_{1}=0.022^{*}, \mathrm{p}_{2}=0.258, \mathrm{p}_{3}=0.001^{*}$ & & \\
\hline
\end{tabular}

$\mathrm{H}$ : $\mathrm{H}$ for Kruskal Wallis test, Pairwise comparison bet. each 2 groups were done using Post Hoc Test (Dunn's for multiple comparisons test) $p: p$ value for comparing between the studied groups $\mathrm{p}_{1}$ : $\mathrm{p}$ value for comparing between Cirrhotic and HCC $\mathrm{p}_{2}$ : $\mathrm{p}$ value for comparing between Cirrhotic and Control $\mathrm{p}_{3}: \mathrm{p}$ value for comparing between HCC and Control

${ }^{*}$ : Statistically significant at $\mathrm{p} \leq 0.05$

Table 6 Comparison between the three studied groups according to BECLIN1

\begin{tabular}{lllll}
\hline BECLIN1 (ng/ml) & $\begin{array}{l}\text { Cirrhotic } \\
(\mathbf{n}=\mathbf{3 0})\end{array}$ & $\begin{array}{l}\text { HCC } \\
(\mathbf{n}=\mathbf{3 0})\end{array}$ & $\begin{array}{l}\text { Control } \\
(\mathbf{n}=\mathbf{2 0})\end{array}$ & H \\
\hline Min. - Max & $1.20-12.0$ & $3.90-19.80$ & $0.70-13.60$ & $22.344^{*}$ \\
Mean \pm SD & $5.62 \pm 2.46$ & $8.65 \pm 3.30$ & $4.49 \pm 3.06$ & $<0.001^{*}$ \\
Median & 5.25 & 7.90 & 4.70 & $3.10-6.60$ \\
IQR & $4.15-6.95$ & $6.20-10.40$ & & \\
Sig. bet. grps & $p_{1}<0.001^{*}, p_{2}=0.200, p_{3}=0.001^{*}$ & & \\
\hline
\end{tabular}

$\mathrm{H}$ : $\mathrm{H}$ for Kruskal Wallis test, Pairwise comparison bet. each 2 groups were done using Post Hoc Test (Dunn's for multiple comparisons test) $p: p$ value for comparing between the studied groups $\mathrm{p}_{1}$ : $\mathrm{p}$ value for comparing between Cirrhotic and HCC $\mathrm{p}_{2}$ : $p$ value for comparing between Cirrhotic and Control $\mathrm{p}_{3}$ : $\mathrm{p}$ value for comparing between $\mathrm{HCC}$ and Control

${ }^{*}$ : Statistically significant at $p \leq 0.05$ 
Table 7 Agreement (sensitivity, specificity) for ATG5, BECLIN1 and AFP to diagnose HCC patients from Cirrhotic

\begin{tabular}{|c|c|c|c|c|c|c|c|c|c|c|}
\hline & \multirow[t]{2}{*}{ AUC } & \multirow[t]{2}{*}{ p } & \multicolumn{2}{|c|}{$95 \%$ C. I } & \multirow[t]{2}{*}{ Cut off" } & \multirow[t]{2}{*}{ Sensitivity } & \multirow[t]{2}{*}{ Specificity } & \multirow[t]{2}{*}{ PPV } & \multirow[t]{2}{*}{ NPV } & \multirow[t]{2}{*}{ Accurac) } \\
\hline & & & LL & UL & & & & & & \\
\hline ATG5(ng/ml) & 0.670 & $0.024^{*}$ & 0.534 & 0.806 & $\leq 95.7$ & 76.67 & 53.33 & 62.2 & 69.6 & 65.0 \\
\hline BECLIN1(ng/ml) & 0.824 & $<0.001^{*}$ & 0.715 & 0.933 & $>5.3$ & 93.33 & 66.67 & 73.7 & 90.9 & 80.0 \\
\hline $\operatorname{AFP}(n g / m l)$ & 0.659 & $0.034^{*}$ & 0.521 & 0.798 & $>70$ & 26.7 & 83.3 & 61.5 & 54.2 & 49.3 \\
\hline \multirow[t]{3}{*}{$p$ value for comparative } & \multicolumn{10}{|c|}{ ATG5 vs. BECLIN1 Z = 1.623, $p=0.105$} \\
\hline & \multicolumn{10}{|c|}{ ATG5 vs. AFP Z $=0.104, p=0.917$} \\
\hline & \multicolumn{10}{|c|}{ BECLIN1 vs. AFP Z $=1.830, p=0.067$} \\
\hline
\end{tabular}

AUC: Area Under a Curve; $p$ value: Probability value

\section{$\mathrm{Cl}$ : Confidence Intervals}

NPV: Negative predictive value; PPV: Positive predictive value

*: Statistically significant at $\mathrm{p} \leq 0.05$

\# Cut off was choose according to Youden index

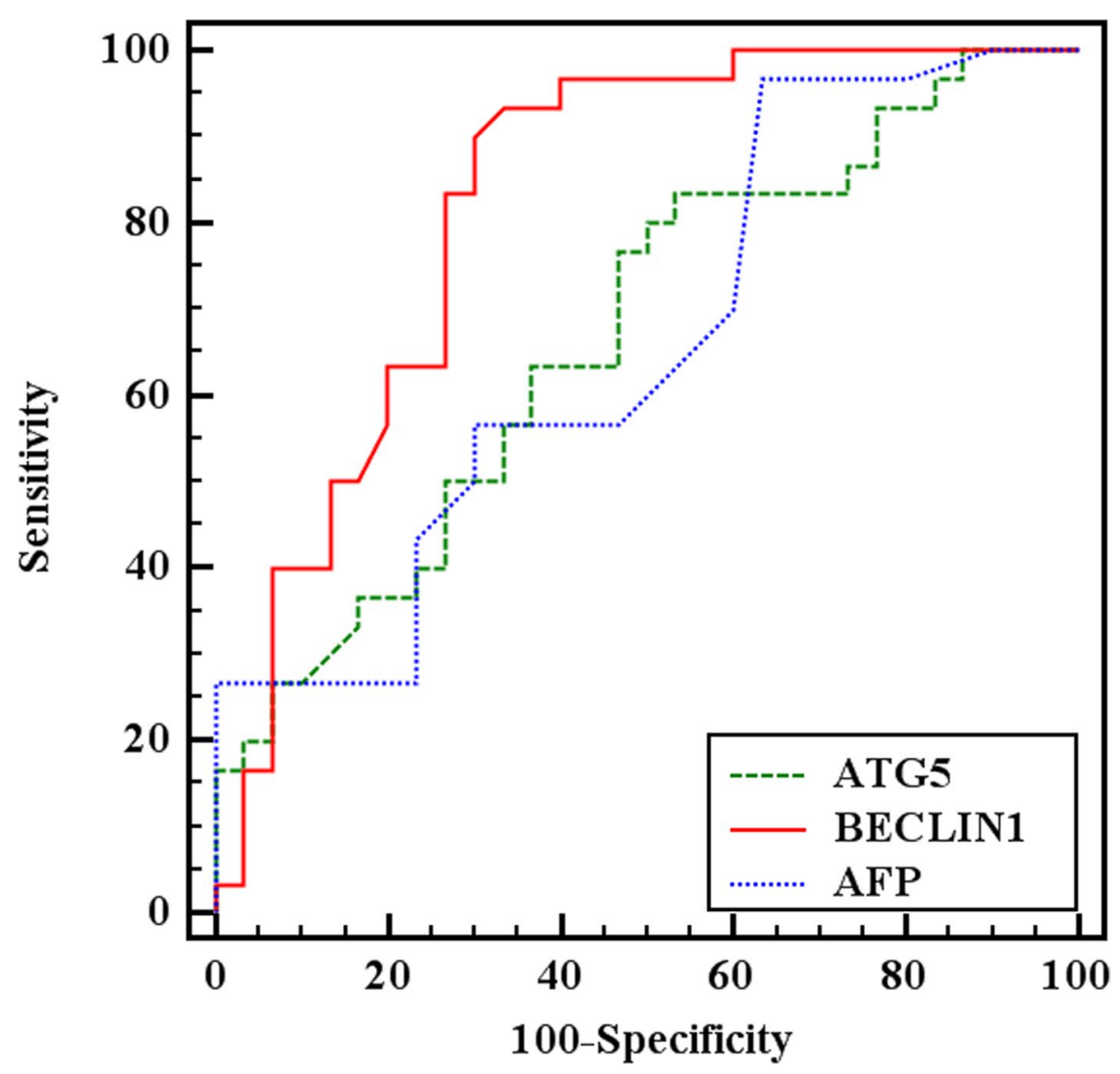

Fig. 1 ROC curve for AFP, ATG5, and BECLIN1 to diagnose HCC patients from cirrhotic patients

assigned 1 point, ATG $5<95.7$ was assigned 1 point, and Beclin $1>5.3$ was given 2. So cachexia, ATG 5, and Beclin1 level were identified as being independently predicting HCC.
The score ranged from 0 to 4 with a cutoff point 2 to predict HCC. At cutoff 2 scoring points, the PPV was $83.3 \%$ and NPV was $75.8 \%$, with (sensitivity 70 , specificity 94\%) as shown in Tables 10 and 11. 
Table 8 Agreement (sensitivity, specificity) for Combined AFP, ATG5 and BECLIN1 to diagnose HCC patients from Cirrhotic

\begin{tabular}{|c|c|c|c|c|c|c|c|c|c|}
\hline \multirow[t]{2}{*}{ Combined } & \multirow[t]{2}{*}{ AUC } & \multirow[t]{2}{*}{$p$} & \multicolumn{2}{|c|}{$95 \%$ C. I } & \multirow[t]{2}{*}{ Sensitivity } & \multirow[t]{2}{*}{ Specificity } & \multirow[t]{2}{*}{ PPV } & \multirow[t]{2}{*}{ NPV } & \multirow[t]{2}{*}{ Accuracy } \\
\hline & & & LL & UL & & & & & \\
\hline ATG5 \& BECLIN1\& AFP & 0.833 & $<0.001^{*}$ & 0.730 & 0.937 & 96.7 & 63.3 & 72.5 & 95.0 & 80.0 \\
\hline
\end{tabular}

AUC: Area Under a Curve p value: Probability value

\section{$\mathrm{Cl}$ : Confidence Intervals}

NPV: Negative predictive value PPV: Positive predictive value

${ }^{*}$ : Statistically significant at $\mathrm{p} \leq 0.05$

Table 9 Multivariate analysis logistic regression for predict HCC

\begin{tabular}{llllll}
\hline Parameters & B (weight) & Sig & OR & \multicolumn{2}{c}{$\mathbf{9 5 \%} \mathbf{C l}$} \\
\cline { 5 - 6 } & & & & LL & UL \\
\hline Cachexia & 1.348 & $0.031^{*}$ & 3.850 & 1.128 & 13.148 \\
ATG5 $(\mathrm{ng} / \mathrm{ml})$ & 1.288 & $0.009^{*}$ & 3.619 & 1.376 & 9.521 \\
BECLIN.1 $(\mathrm{ng} / \mathrm{ml})$ & 1.70 & $0.018^{*}$ & 5.460 & 1.340 & 22.244 \\
Child class & 0.076 & 0.931 & 0.926 & 0.164 & 5.230 \\
AFP(ng/ml) & -0.475 & 0.620 & 0.622 & 0.095 & 4.075 \\
\hline
\end{tabular}

Table 10 Cutoff and scoring points for the different parameters

\begin{tabular}{lll}
\hline Parameters & Cutoff & $\begin{array}{l}\text { Scoring } \\
\text { points }\end{array}$ \\
\hline Cachexia & - & 1 \\
ATG5 $(\mathrm{ng} / \mathrm{dl})$ & 95.7 & 1 \\
BECLIN.1(ng/dl) & 5.3 & 2 \\
\hline
\end{tabular}

Table 11 Cutoffs, sensitivity and specificity for the total score

\begin{tabular}{lllll}
\hline Criterion & Sensitivity & Specificity & + PV & -PV \\
\hline$\geq 0$ & 100.00 & 0.00 & 37.5 & \\
$>0$ & 80.00 & 58.00 & 53.3 & 82.9 \\
$>1$ & 63.33 & 76.00 & 61.3 & 77.6 \\
$>2$ & 70.00 & 94.00 & 83.3 & 75.8 \\
$>3$ & 30.00 & 98.00 & 90.0 & 70.0 \\
$>4$ & 0.00 & 100.00 & & 62.5 \\
\hline
\end{tabular}

\section{Discussion}

Hepatocellular carcinoma (HCC) counts around 90\% of primary liver cancers. The poor prognosis of patients with HCC is due to a late diagnosis. Therefore, it is important to detect new biomarkers which can be used as complements or substitutes for AFP in HCC diagnosis and to be a proper tool for assessment of tumor spread and patient prognosis as these markers can be a tool for HCC treatment and outcomes $[17,18]$.
Autophagy is a degradation of lysosomes which is important for cell survival under starvation, stress, and infection. The mechanism is regenerating of energy from intracellular materials (cytoplasm, organelles, protein aggregates, etc.) to meet energy requirements in lownutritional conditions [19].

In this study, serum ATG 5 was significantly lower in patients with $\mathrm{HCC}$ than in patients with cirrhosis, but there was no statistically significant difference between patients with cirrhosis than control individuals. The ROC curve for ATG5 for detection of HCC from cirrhosis was significant, its diagnostic performance was $0.670^{*}$ $\left(p<0.024^{*}\right)$, and the cutoff point discriminating HCC from liver cirrhosis was $<95.7$ with sensitivity of $76.6 \%$, specificity of $53.33 \%$, positive predictive value of $62.2 \%$, negative predictive value of $69.9 \%$, and accuracy of $65 \%$.

This is in concordance with Yang et al. [20] who found that Atg5 were decreased in human HCC tissue in comparison with control tissue which suggests that autophagy is decreased in HCC. Also, this result is consistent with findings in Takamura et al's [21] study that autophagy might be a suppressor mechanism in HCC. Therefore, autophagic deficiency increases tumor growth in HCC.

In this study, serum Beclin 1 was significantly higher in HCC patients than patients with cirrhosis but there was no statistically significant difference between patients with cirrhosis than control individuals ( $p$ value $<0.001$ ).

The ROC curve for Beclin 1 for detection of HCC from liver cirrhosis was significant, its diagnostic performance was $0.824(p<0.001)$, and the cutoff point discriminating HCC from cirrhosis was $>5.3$ with sensitivity of 93.33 , specificity of $66.67 \%$, positive predictive value of $73.3 \%$, negative predictive value of $90.9 \%$, and accuracy of $80 \%$.

In contrast to the results of Qiu et al. [22] that have detected that Beclin1 expression in HCC is significantly lower than that in normal and cirrhotic tissues. They have also shown that Beclin1 expression is correlated with liver cirrhosis and vascular invasion but not with TNM stage, AFP level, number of tumors, and capsule.

In this study, we developed a simple score that consisted of routinely available clinical and laboratory 
parameters to predict the risk of $\mathrm{HCC}$ in patients with $\mathrm{HCV}$-related cirrhosis. This prediction score is accurate. The score ranged from 0 to 4 , it is composed of Cachexia which was assigned 1 point since its estimated coefficient in logistic regression model was 1.348 , ATG $5<95.7$ was assigned 1 point as its estimated coefficient I logistic regression model was 1.288 , and Beclin $1>5.3$ was given 2 points for its estimated coefficient in logistic regression model was 1.7.

A cutoff point 2 is used to predict HCC in HCV-related cirrhotic patients. At cutoff value of 2 scoring points, the PPV was $83.3 \%$ and NPV was $75.8 \%$. Using a cutoff of 2 points led to false negative results in 4 out of 30 with HCC (sensitivity $70 \%$, specificity $94 \%$ ).

Compared with current guidelines, the prediction score provides more systematic stratification of HCC risk $[23,24]$.

The score suggests that patients with cachexia can predict the development of HCC. And this is consistent with Nozoe et al. [25], who used the prognostic nutritional index (PNI) as a prognostic marker in a number of gastrointestinal malignancies, and more recently, in a study by Proctor et al. [26], the PNI was found to affect the prognosis in malignancy regardless of the site of origin.

Also, in this study, assessment of serum marker may have the advantage of being noninvasive rather than other studies in which assessment of Beclin 1 and ATG 5 used the invasive technique by liver biopsy.

\section{Conclusion}

Serum Beclin 1 and ATG 5 could be used as a novel diagnostic marker for HCC. Moreover, scoring of serum BECLIN 1, ATG 5, and cachexia might be a future promising tool to predict the risk of HCC development.

\section{Limitation of this study}

Small number of patients therefore studying on a large number of patients could be suggested.

\section{Recommendation}

Wide sample sizes are suggested to validate this result.

\section{Abbreviations \\ HCV: Hepatitis C virus; HCC: Hepatocellular carcinoma; ATG 5: Autophagy- related protein 5; BCLC: Barcelona Clinic Liver Cancer.}

\section{Acknowledgements}

The authors are thankful to the Tropical Medicine Department, Faculty of Medicine, Alexandria University.

\section{Authors' contributions}

SB was responsible for the practical section, analysis of data, and manuscript preparation. The authors read and approved the final manuscript.

\section{Funding}

No particular support from publicly supported, financially, or non-profit organizations has been granted in this research.

\section{Availability of data and materials}

The published article [and its supplementary information files] contains all the data produced or analyzed during this research.

\section{Declarations}

\section{Ethics approval and consent to participate}

The Ethical Committee (EC) at our institution approved the study. The EC has FWA since 2010 and operates according to the ICH GCP guidelines and applicable local and institutional regulations and guidelines (serial number of ethical approval 0201134) (FWA no. 00018699 expires January 21, 2026) (IRB no. 00012098 expires June 10, 2022). Patients included in the study signed an informed written consent to participate.

\section{Consent for publication}

Not applicable.

\section{Competing interests}

The authors declare that they have no competing interests.

\section{Author details}

${ }^{1}$ Tropical Medicine Department, Faculty of Medicine, Alexandria University, Alexandria, Egypt. ${ }^{2}$ Clinical Pathology Department, Faculty of Medicine, Alexandria University, Alexandria, Egypt.

Received: 31 May 2021 Accepted: 18 September 2021

Published online: 15 October 2021

\section{References}

1. Akinyemiju T, Abera S, Ahmed M, Alam N, Alemayohu MA, Allen C, AlRaddadi R, Alvis-Guzman N, Amoako Y et al (2017) The burden of primary liver cancer and underlying etiologies from 1990 to 2015 at the global, regional, and national level: results from the Global Burden of Disease Study 2015. JAMA Oncol 3(12):1683-1691

2. Sangiovanni A, Prati GM, Fasani P, Ronchi G, Romeo R, Manini M, Del Ninno E, Morabito A, Colombo M (2006) The natural history of compensated cirrhosis due to hepatitis C virus: A 17-year cohort study of 214 patients. Hepatology 43(6):1303-1310

3. Dash S, Chava S, Chandra PK, Aydin Y, Balart LA, Wu T (2016) Autophagy in hepatocellular carcinomas: from pathophysiology to therapeutic response. Hepat Med 8:9-20

4. Lazova R, Camp RL, Klump V, Siddiqui SF, Amaravadi RK, Pawelek JM (2012) Punctate LC3B expression is a common feature of solid tumors and associated with proliferation, metastasis, and poor outcome. Clin Cancer Res 18(2):370-379

5. Wu DH, Jia CC, Chen J, Lin ZX, Ruan DY, Li X, Lin Q, Min D, Ma XK et al (2014) Autophagic LC3B overexpression correlates with malignant progression and predicts a poor prognosis in hepatocellular carcinoma. Tumour Biol 35(12):12225-12233

6. Li J, Yang B, Zhou Q, Wu Y, Shang D, Guo Y, Song Z, Zheng Q, Xiong J (2013) Autophagy promotes hepatocellular carcinoma cell invasion through activation of epithelial-mesenchymal transition. Carcinogenesis 34(6):1343-1351

7. Liang XH, Yu J, Brown K, Levine B (2001) Beclin 1 contains a leucine-rich nuclear export signal that is required for its autophagy and tumor suppressor function. Cancer Res 61(8):3443-3449

8. Qu X, Yu J, Bhagat G, Furuya N, Hibshoosh H, Troxel A, Rosen J, Eskelinen EL, Mizushima N et al (2003) Promotion of tumorigenesis by heterozygous disruption of the beclin 1 autophagy gene. J Clin Invest 112(12):1809-1820 
9. Yousefi S, Perozzo R, Schmid I, Ziemiecki A, Schaffner T, Scapozza L, Brunner T, Simon HU (2006) Calpain-mediated cleavage of Atg5 switches autophagy to apoptosis. Nat Cell Biol 8(10):1124-1132

10. Xia HG, Zhang L, Chen G, Zhang T, Liu J, Jin M, Ma X, Ma D, Yuan J (2010) Control of basal autophagy by calpain 1 mediated cleavage of ATG5. Autophagy 6(1):61-66

11. Tekirdag KA, Korkmaz G, Ozturk DG, Agami R, Gozuacik D (2013) MIR181A regulates starvation- and rapamycin-induced autophagy through targeting of ATG5. Autophagy 9(3):374-385

12. Medline plus (2020) Alpha-fetoprotein (AFP) test. https://medlineplus. gov/lab-tests/alpha-fetoprotein-afp-test/. Accessed 28 April 2021

13. Novus Biologicals (2020) Novus Biologicals. Human Beclin 1 ELISA Kit (Colorimetric). https://www.novusbio.com/products/beclin-1-elisa-kit_ nbp2-69959;2020. Accessed 28 April 2021.

14. Cloud-Clone Corp (2020) SEL221Hu 96 tests enzyme-linked immunosorbent assay kit for autophagy related protein 5 (ATG5) organism species: Homo sapiens (human) instruction manual. http://www.cloud-clone. com/manual/ELISA-Kit-for-Autophagy-Related-Protein-5-(ATG5)-SEL22 1 Hu.pdf. Accessed 6 March 2020.

15. Kotz S, Balakrishnan N, Read CB, Vidakovic B (2006) Encyclopedia of statistical sciences. 2nd ed. Wiley-Interscience, Hoboken, N.J.

16. Kirkpatrick LA, Feeney BC (2013) A simple guide to IBM SPSS statistics for version 20.0. Student ed. Wadsworth, Cengage Learning, Belmont, Calif.

17. Kim DY, Han KH (2012) Epidemiology and surveillance of hepatocellular carcinoma. Liver Cancer 1(1):2-14

18. Zhu K, Dai Z, Zhou J (2013) Biomarkers for hepatocellular carcinoma: progression in early diagnosis, prognosis, and personalized therapy. Biomark Res 1(1):10

19. He C, Klionsky DJ (2009) Regulation mechanisms and signaling pathways of autophagy. Annu Rev Genet 43:67-93
20. Yang J, He Y, Zhai N, Ding S, Li J, Peng Z (2018) MicroRNA-181a inhibits autophagy by targeting Atg5 in hepatocellular carcinoma. Front Biosci (Landmark Ed) 23:388-396

21. Takamura A, Komatsu M, Hara T, Sakamoto A, Kishi C, Waguri S, Eishi Y, Hino O, Tanaka K et al (2011) Autophagy-deficient mice develop multiple liver tumors. Genes Dev 25(8):795-800

22. Qiu DM, Wang GL, Chen L, Xu YY, He S, Cao XL, Qin J, Zhou JM, Zhang YX et al (2014) The expression of beclin-1, an autophagic gene, in hepatocellular carcinoma associated with clinical pathological and prognostic significance. BMC Cancer 14:327

23. Ueno S, Tanabe G, Sako K, Hiwaki T, Hokotate H, Fukukura Y, Baba Y, Imamura Y, Aikou T (2001) Discrimination value of the new western prognostic system (CLIP score) for hepatocellular carcinoma in 662 Japanese patients. Cancer of the Liver Italian Program. Hepatology 34(3):529-534.

24. Bruix J, Sherman M (2005) Management of hepatocellular carcinoma. Hepatology 42(5):1208-1236

25. Nozoe T, Kohno M, Iguchi T, Mori E, Maeda T, Matsukuma A, Ezaki T (2012) The prognostic nutritional index can be a prognostic indicator in colorectal carcinoma. Surg Today 42(6):532-535

26. Proctor MJ, Morrison DS, Talwar D, Balmer SM, Fletcher CD, O'Reilly DS, Foulis AK, Horgan PG, McMillan DC (2011) A comparison of inflammationbased prognostic scores in patients with cancer. A Glasgow Inflammation Outcome Study. Eur J Cancer 47(17):2633-2641

\section{Publisher's Note}

Springer Nature remains neutral with regard to jurisdictional claims in published maps and institutional affiliations.

\section{Submit your manuscript to a SpringerOpen ${ }^{\circ}$ journal and benefit from:}

- Convenient online submission

- Rigorous peer review

- Open access: articles freely available online

- High visibility within the field

- Retaining the copyright to your article

Submit your next manuscript at $\boldsymbol{\nabla}$ springeropen.com 